\title{
A ELABORAÇÃO NARRATIVA NO ABUSO SEXUAL: O PAPEL DAS VÍTIMAS ENQUANTO PROTAGONISTAS NO PROCESSO DE MUDANÇA
}

\author{
Carla Antunes ${ }^{1}$ \\ Carla Machado ${ }^{2}$
}

[Enviado a 01-10-2012. Aceite a 23-12-2012]

\begin{abstract}
Resumo: A investigação no domínio do abuso sexual na infância e adolescência tem vindo a reportar uma variedade de potenciais consequências adversas da experiência abusiva no desenvolvimento das vítimas, sendo relativamente escasso o estudo dos fatores que caracterizam as trajetórias desenvolvimentais adaptativas/resilientes. Neste sentido, foi realizado um estudo com vítimas de abuso sexual (a partir do modelo narrativo de White e Epston), cujo objetivo passou pela compreensão da experiência de abuso e dos processos de mudança associados. Foram realizadas 16 entrevistas qualitativas em profundidade com vítimas de abuso sexual, cujos dados foram submetidos a um processo de grounded analysis e de codificação através do Sistema de Codificação dos Momentos de Inovação (MIs). Os resultados refletem uma considerável diversidade de MIs, sendo o MI mais saliente o de Reflexão, enquanto o de Reconceptualização surge sub-representado. Os recursos identificados pelas crianças/jovens para a mudança incluem essencialmente a dimensão de suporte social (pares, família e professores), sendo a revelação, as expectativas de justiça, as crenças religiosas e a construção de novas significações para o self dimensões que reforçam a perceção de competência pessoal e controlo. $\mathrm{O}$ modelo narrativo revelou-se útil na compreensão das dinâmicas de significação destas crianças/jovens em torno do seu processo de mudança, sendo de salientar o seu papel enquanto "protagonistas" ativos nas suas narrativas pessoais de abuso.
\end{abstract}

Palavras-chave: abuso sexual, modelo narrativo, recursos para a mudança, momentos de inovação

\footnotetext{
${ }^{1}$ Escola de Psicologia, Universidade do Minho, Campus de Gualtar, 4710 Braga, E-mail: cantunes94@gmail.com

2 Escola de Psicologia, Universidade do Minho
} 
Narrative construction of sexual abuse: The role of victims as actors in the process of change (Abstract): The research on sexual abuse in childhood and adolescence has been reporting a variety of potential adverse consequences of abusive experience in the victims' development, but it is relatively scarce on the factors that characterize the adaptive/resilient development. In this sense, a study was conducted with victims of sexual abuse (based on the narrative model of White and Epston), whose purpose was to understand the abusive experience and the associated change processes. 16 in-depth qualitative interviews were conducted with victims of sexual abuse and the data was submitted to a process of grounded analysis and coding, using the of Innovation Moments Coding System. The results reflect a considerable diversity of IMs, with Reflection as the most salient IM while Reconceptualization appears underrepresented. The change resources identified by the children include social support (peers, family and teachers), the disclosure, expectations of justice, religious beliefs and the construction of new meanings for the self. These resources were viewed as dimensions that reinforce the personal competence and the perception of control. The narrative model was useful in understanding the dynamics of meaning of the process of change, emphasizing the role of children as active "protagonists" of their personal narratives of abuse.

Keywords: sexual abuse, narrative model, change resources, innovation moments

\section{Introdução}

O abuso sexual foi reconhecido como um problema social no início dos anos oitenta, na sequência de um conjunto de estudos epidemiológicos que revelaram indicadores de prevalência verdadeiramente assustadores (Haugaard, 2000; Machado 2002). Em Portugal, o interesse por este objeto de estudo é ainda mais recente e o investimento na sua abordagem científica é ainda bastante circunscrito, ainda que os dados disponíveis de fontes oficiais e de estudos científicos realizados demonstrem que o abuso sexual é, também no nosso País, uma realidade não negligenciável.

A par do crescente reconhecimento do impacto do abuso no desenvolvimento da criança e/ou jovem vítima, a investigação tem largamente negligenciado o estudo dos fatores que caracterizam as trajetórias desenvolvimentais resilientes identificadas em muitas crianças abusadas (Kendall-Tackett, Williams, \& Finkelhor, 1993; Saywitz, Mannarino, Berliner, \& Cohen, 2000). Efetivamente, esta é ainda uma área pouco explorada e cuja compreensão é também dificultada pelos próprios problemas de conceptualização da resiliência (Heller, Larrieu, D’Imperio \& Boris, 1999). Na verdade, existem vários modelos teóricos explicativos da resiliência (e.g., modelo da 
psicopatologia do desenvolvimento; Cicchetti \& Lynch, 1995, Joyce-Moniz, 1993; Soares, 2000; modelo bioecológico do desenvolvimento, Bronfenbrenner, 1994), mas poucos têm sido explicitamente aplicados ao abuso sexual, sendo ainda menos os que foram especificamente concebidos para compreender, quer o impacto, quer os processos de mudança após a experiência de abuso (e.g., modelo das dinâmicas traumáticas; Finkelhor, 1990). Também nesta dimensão, a atenção aos processos de significação das vítimas e à forma como estes promovem ou restringem os percursos das crianças/jovens em direção à mudança tem sido relativamente esquecida.

\section{Modelo Narrativo de reautoria: relevância dos "Momentos de Inovação"}

O modelo narrativo de reautoria, de White e Epston (1990) inscreve-se num conjunto de abordagens teóricas que advogam que as experiências só adquirem significado e coerência a partir do seu enquadramento em narrativas, sendo que a forma como damos sentido ao mundo e a nós próprios se faz a partir da construção e desconstrução de histórias (Freedman, \& Combs, 1996; Gonçalves, \& Henriques, 2000; Gonçalves 2008; White, \& Epston, 1990). Neste sentido, mais do que meros protagonistas nestes argumentos, somos coautores das identidades que construímos narrativamente, sendo estas reescritas constantemente. De acordo com esta perspetiva, o desenvolvimento de uma narrativa problemática deriva de uma centração repetitiva do indivíduo em narrativas que mantêm o problema dominante e reforçam as significações de desvalorização construídas em torno dele. Neste quadro, há uma clara dificuldade do indivíduo em aceder a narrativas alternativas disponíveis e em desenvolver formas de vida preferenciais e mais satisfatórias. Esta dificuldade poderá decorrer, por um lado, do facto de estas narrativas alternativas se revelarem ténues no seu enquadramento social e cultural, e pela ausência de validação social destas alternativas, por outro lado, é também possível que a sua narrativa dominante obstrua o acesso do individuo à narrativa alternativa (White \& Epston, 1990; Gonçalves, 2008).

Partindo desta premissa, esta abordagem assume que os problemas não existem "dentro" das pessoas mas num espaço discursivo que os legitima e os sustenta (Freedman, \& Combs, 1996; Gonçalves, \& Henriques, 2000; Gonçalves, 2008, White, \& Epston, 1990). Deste modo, esta perspetiva contraria a internalização do problema como um "defeito" e a subsequente patologização do indivíduo. Esta leitura narrativa abre, assim, a possibilidade de situar os problemas nos contextos de vida dos sujeitos, sendo, portanto, passíveis de serem desafiados, contra-argumentados e re-significados. 
Este processo de externalização do problema (White, \& Epston, 1990), ingrediente essencial na ótica narrativa, é facilitado por uma atitude discursiva interpessoal (nomeadamente terapêutica) que sistematicamente diferencie o indivíduo da sua história problemática (Freedman, \& Combs, 1996; White, 1994, cit. Gonçalves, 2008). Neste contexto de curiosidade, e precisamente para abrir "a porta" a significações e comportamentos que se situem fora da lógica do problema, incentiva-se o sujeito a refletir acerca das suas interpretações, competências e soluções, sendo estes elementos comummente silenciados pela versão problemática dominante (Freedman, \& Combs, 1996; Gonçalves, 2008; Machado, \& Gonçalves, 1999; White \& Epston, 1990).

Estes momentos que resistem e/ou escapam à influência do problema e que contradizem as prescrições problemáticas são designados por White e Epston (1990) de "resultados únicos". Também de acordo com os pressupostos conceptuais deste modelo, os seres humanos são multipotenciais e, como tal, estes momentos de resistência estão presentes em todas as histórias, mesmo nas mais problemáticas. Estes "resultados únicos" foram posteriormente designados por Gonçalves, Matos, e Santos (2009) por "momentos de inovação"3 e podem assumir-se como ações, cognições, desejos e/ou expectativas, percecionadas pelo próprio ou pelos seus outros significativos. De igual modo, podem ocorrer no plano da concretização ou da imaginação e em diferentes dimensões temporais (passado, presente ou futuro) (Freedman, \& Combs, 1996; Gonçalves, \& Henriques, 1999; Gonçalves, 2008). A exploração dos momentos de inovação constitui-se como uma oportunidade de antecipar cenários libertos da influência da auto-narrativa problemática e de ensaiar novas formas de sentir/pensar/agir, impulsionando a perceção de poder e de autoria do sujeito, bem como um maior sentido de proactividade perante a sua própria vida (Freedman, \& Combs, 1996; Gonçalves, \& Henriques, 2000; Gonçalves, 2008; White, 2004). Deste processo resultará, segundo este modelo, um momento em que o indivíduo "começa a ensaiar

\footnotetext{
${ }^{3}$ Para a clarificação da opção dos autores (e nossa, neste artigo, de ora em diante) pela designação "momentos de inovação", em detrimento de "resultados únicos", consultar Gonçalves, Matos, e Santos (2009). Em síntese, estes autores argumentam que a denominação proposta por White e Epston (1990) poderá conduzir a leituras ambíguas daquilo em que consistem estes momentos. Por um lado, a denominação de "resultado" poderá remeter para uma ideia de "produto terapêutico", quando na verdade estas ocorrências são parte integrante de um processo de mudança, nunca inteiramente finalizado, e sempre aberto e em construção. Por outro lado, o termo "único" poderá induzir os leitores a pensar que estes momentos que contrastam com a narrativa problemática surgem de forma isolada nas histórias dos indivíduos. Neste sentido e assumindo que os RU's se constituem como elementos que ocorrem frequentemente nas vidas de qualquer pessoa, ainda que possam não ser notados ou não ser elaborados, a designação de "inovação" parece ser mais adaptada ao processo que a designação pretende caracterizar.
} 
novas formas de se relacionar com o problema" (Gonçalves, 2008, p. 58), dando origem à emergência e progressiva consolidação de uma nova versão da sua identidade (Gonçalves, \& Henriques, 2001; Gonçalves, 2008).

No modelo narrativo da reautoria, este processo de mudança, assim como as formas de o promover, têm sido sobretudo descritas no contexto terapêutico. Há, contudo, algumas propostas que tentam aplicar este modelo explicativo aos processos de mudança espontânea que ocorrem na vida das pessoas (e.g., Cruz, 2008; Meira, 2010), tendo a investigação empírica neste domínio verificado que tais processos são largamente semelhantes aos ocorridos no âmbito da mudança terapêutica.

Em suma, numa leitura narrativa dos processos de resiliência, nem todas as vítimas desenvolvem narrativas colonizadas pelo abuso e a história problemática é apenas uma das múltiplas versões possíveis para dar sentido às suas vidas e experiências (Harker, 1997). Estas crianças possuem competências e recursos para desafiar os significados e prescrições comportamentais ditados pela narrativa problemática e para construir narrativas alternativas, mais libertadoras e preferenciais (Adams-Westcott, \& Dobbins, 1997). Com base nestes pressupostos narrativos, no presente estudo, pretendemos explorar, através de uma grelha conceptual narrativa, os recursos narrativos das crianças e/ou jovens vítimas de abuso sexual para resistirem ao impacto adverso da experiência abusiva e construírem ações e significações preferenciais.

\section{Método}

\section{Participantes}

A amostra é constituída por dezasseis vítimas de abuso sexual (dez do sexo feminino e seis do sexo masculino), com idades compreendidas entre os doze e os dezasseis anos de idade $(\mathrm{M}=13.75$; S.D. $=1.19)$. Relativamente às características do abuso, dez são casos de abuso extrafamiliar e seis casos de abuso intrafamiliar. A diferença de idades entre ofensor e vítima variou entre 15 e 44 anos $(M=28,1 ;$ S.D. $=9.78)$. Dos dezasseis casos, três envolveram o uso da força e ameaças e duas das vítimas masculinas relataram o recurso a armas. No que se refere às características dos cuidadores, as idades dos pais e/ou substitutos variam entre trinta e sete e sessenta e oito anos de idade $(\mathrm{M}=45$; S.D. $=7.65)$ e as das mães e/ou substitutas entre trinta e um e cinquenta e dois anos $(\mathrm{M}=40$; S.D. $=5.57)$, sendo, na sua maioria, casados. Os participantes fizeram ainda referência a outras problemáticas familiares, destacando-se a presença de problemas de saúde mental (44\%) dos progenitores e/ou seus substitutos (e.g., alcoolismo e/ou consumo de drogas; depressão) e a experienciação de outras formas de vitimação concomitantes (44\%) (e.g., exposição a violência interparental, maus tratos físicos e/ou psicológicos). 


\section{Instrumentos}

Entrevista qualitativa em profundidade: esta entrevista foi elaborada intencionalmente para este estudo, com base no modelo narrativo de reautoria de White e Epston (1990), sendo constituída por questões em torno de três áreas fundamentais: (a) questões em torno da desconstrução do problema, identificando a sua área de influência, as suas estratégias, prescrições e figuras que o alimentam (e.g., "O problema ainda te aborrece? O que é que o medo te leva a fazer? O que é que a culpa diz sobre ti? Há alguma coisa na maneira de ser das pessoas à tua volta que ajuda o problema?); (b) o questionamento minucioso sobre eventuais momentos e/ou áreas que escapam à influência do problema (e.g., "Há alturas em que consigas desobedecer ao problema? Como é que conseguiste fazer isso? Que pensamentos é que te ajudaram?); e (c) questões dirigidas ao significado pessoal dos momentos de inovação (e.g., "O que é que o facto de teres sido capaz de contar diz sobre ti? O que é que há em ti que te levou a seres capaz de fazer isto? O que é que isto diz sobre o teu futuro?").

Processos de avaliação forense: foram analisados os processos que decorriam na Unidade de Consulta de Psicologia da Justiça na Universidade do Minho e na Associação "Chão dos Meninos", no sentido de aferir se os avaliados correspondiam aos critérios de amostragem explicitados de seguida. Neste sentido, as perícias realizadas foram alvo de análise, de forma obter informação acerca das experiências de abuso sexual, designadamente, o seu contexto de ocorrência e o parecer formulado pelo perito relativamente à credibilidade dos relatos produzidos pelas vítimas.

\section{Procedimentos}

\section{Critérios de amostragem}

O processo de constituição da amostra no presente estudo pautou-se pelas orientações da amostragem teórica intencional (Flick, 2002), visando, essencialmente, atingir a representatividade do fenómeno do abuso sexual, ampliando o conhecimento sobre o mesmo através da exploração da experiência idiossincrática de cada um dos participantes, considerados por nós como peritos experienciais (Morse, 1994).

De forma a garantir o rigor e a objetividade metodológica na prossecução deste estudo, foi definido um conjunto de critérios para a seleção da amostra: a) a criança/jovem ter sido sinalizada pelo Tribunal após uma denúncia de abuso sexual; b) existir um parecer positivo da avaliação forense quanto à credibilidade das alegações de abuso realizadas (uma vez que em parte dos casos de abuso acessíveis não havia ainda decisão judicial final, 
embora em todos houvesse acusação, assim garantindo, também no plano legal, a elevada probabilidade de ocorrência dos factos); c) a criança/jovem ter capacidades comunicativas e intelectuais suficientes para a produção de um relato adequado dos factos abusivos e para ser capaz de responder às questões integrantes do guião de entrevista (estas capacidades intelectuais e narrativas são alvo de avaliação desenvolvimental no âmbito do protocolo de avaliação do abuso usado na Unidade de Psicologia da Justiça na Universidade do Minho); e d) a criança/jovem não ter sido alvo de intervenção psicoterapêutica.

Assim, entre 2005 e 2008 as autoridades judiciais encaminharam diversas crianças e jovens, alegadamente vítimas de abuso sexual, para a Unidade de Psicologia da Justiça do Serviço de Psicologia da Universidade do Minho, com o pedido de se proceder à sua avaliação forense. No final deste processo de avaliação e emissão do parecer solicitado, e caso os menores preenchessem os critérios de amostragem previamente definidos, os psicólogos responsáveis pelos processos explicitavam aos representantes legais dos menores e aos próprios os objetivos e procedimentos do presente estudo, bem como a salvaguarda da confidencialidade e do anonimato na apresentação pública dos resultados, questionando-os sobre a sua disponibilidade para participar no estudo.

\section{Análise dos dados}

Após a recolha e posterior transcrição das entrevistas, foi iniciado o processo de codificação e análise dos dados obtidos, utilizando para tal o programa Non-numerical Unstructured Data - Indexing, Searching and Theorizing - NUD*IST (Qualitative Solutions and Research, 1997). Através do recurso a este suporte informático, desenvolvemos uma categorização indutiva e exaustiva de todo o texto, tomando a frase como unidade de análise.

Este processo iniciou-se com uma primeira análise preliminar de quatro casos, que permitiu identificar os principais temas gerais presentes nas narrativas dos participantes. De acordo com o modelo narrativo de reautoria proposto por White e Epston (1990) estes conteúdos organizavam-se em torno de duas áreas fundamentais: a) influência do problema (evolução, efeitos, prescrições, normativas sociais e/ou culturais); e b) momentos de inovação (Gonçalves, Matos \& Santos, 2009), que traduziam momentos de exceção à narrativa problemática. Deste modo, numa etapa posterior, a codificação dos dados empíricos foi orientada segundo procedimentos distintos no que se refere ao impacto do abuso e aos momentos de inovação. No presente artigo, por uma questão de limitação de espaço, são analisados apenas os dados relativos aos momentos de inovação. 


\section{Codificação dos Dados}

Utilizámos um sistema de codificação desenvolvido pelo grupo de investigação que, na Universidade do Minho, se tem dedicado ao estudo do papel dos momentos de inovação nos processos de mudança, terapêutica e espontânea - Sistema de Codificação dos Momentos de Inovação (SCMI; Gonçalves, Ribeiro, Mendes, Matos, \& Santos, 2011). Dos estudos subjacentes à construção do sistema de codificação (Matos, Santos, Gonçalves, \& Martins, 2009; Gonçalves, Cunha, Ribeiro, Mendes, Santos, Matos, \& Salgado, 2010), emergiram cinco categorias de momentos de inovação, conforme se encontra sistematizado no Quadro I: (1) Ação, (2) Reflexão, (3) Protesto, (4) Reconceptualização e (5) Desempenho da mudança.

De acordo com o protocolo estabelecido no âmbito do Sistema de Codificação dos Momentos de Inovação (SCMI 7.2, Gonçalves, Matos, \& Santos, 2008, 2010), os investigadores que pretendam recorrer a este instrumento devem realizar um processo de treino prévio, constituído por diferentes etapas, desde um conhecimento teórico rigoroso do sistema até à sua aplicação. A primeira autora deste trabalho submeteu-se, assim, ao processo de treino de codificação definido pelos autores do sistema (SCMI 7.2, Gonçalves, Matos, \& Santos, 2008, 2010). Tal como recomendado pelos autores, a codificação dos dados foi efetuada com recurso a dois codificadores. O juiz principal (primeira autora deste trabalho) codificou 100\% das entrevistas e juiz co-codificador codificou $50 \%$, tomando em consideração a análise de dois parâmetros: a) o tipo de momento de inovação (e.g., ação, reflexão, protesto, reconceptualização, desempenho da mudança), e b) a saliência temporal de cada momento de inovação ao longo da entrevista (i.e., tempo ocupado por cada MI), sendo posteriormente também ponderado o índice de saliência temporal de cada tipo de MI (i.e., através do somatório do tempo ocupado por cada um dos tipos de MIs é calculada a sua proporção em função do tempo total da entrevista). Após a conclusão do procedimento de codificação foi calculada a percentagem de acordo interjuízes no que se refere à saliência dos MIs identificados (96\%) e o Kappa de Cohen relativamente aos diferentes tipos de MIs (0.92). Atendendo ao nível elevado de fidelidade, os resultados que apresentaremos neste estudo resultam da codificação realizada pela juíza principal. 


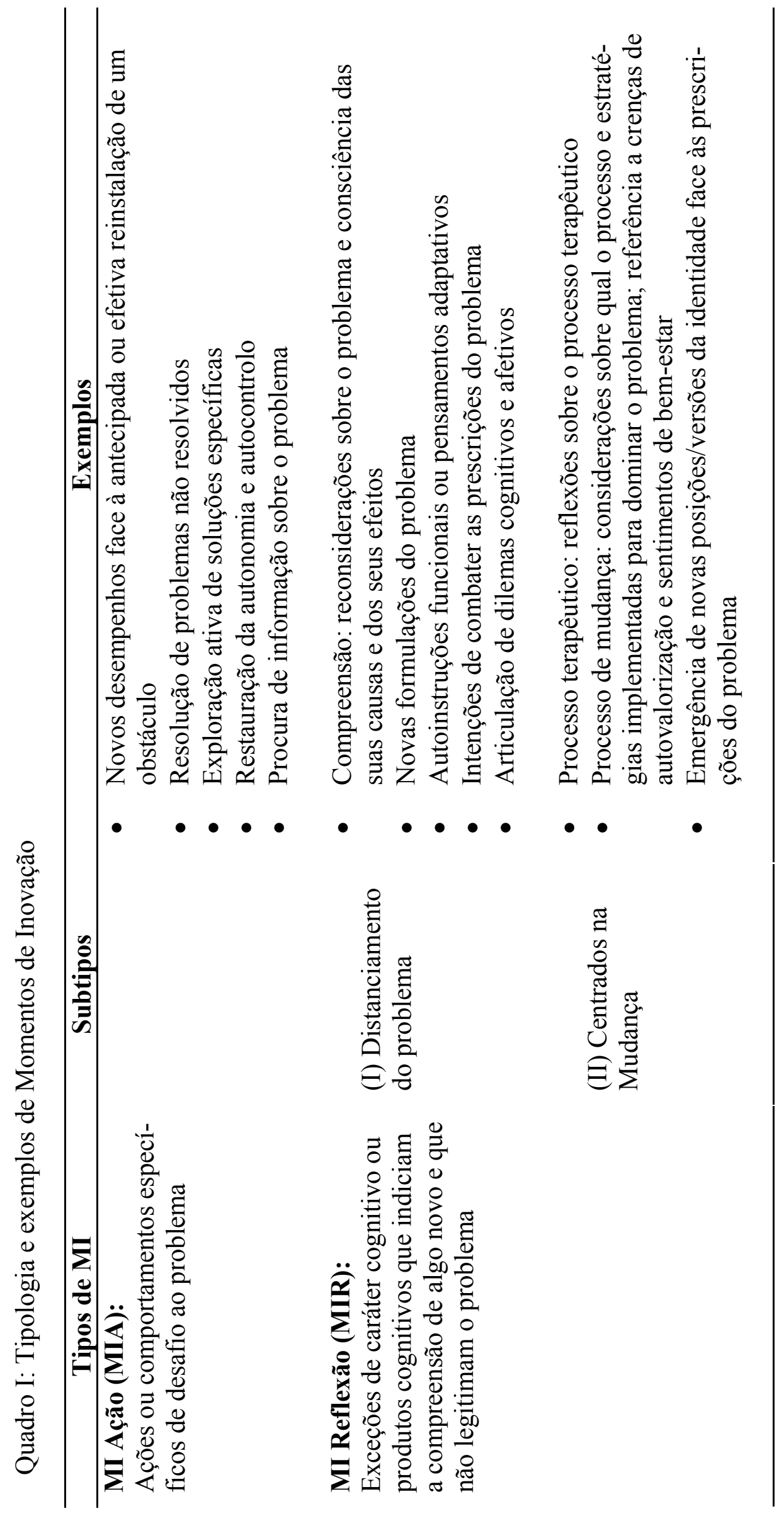




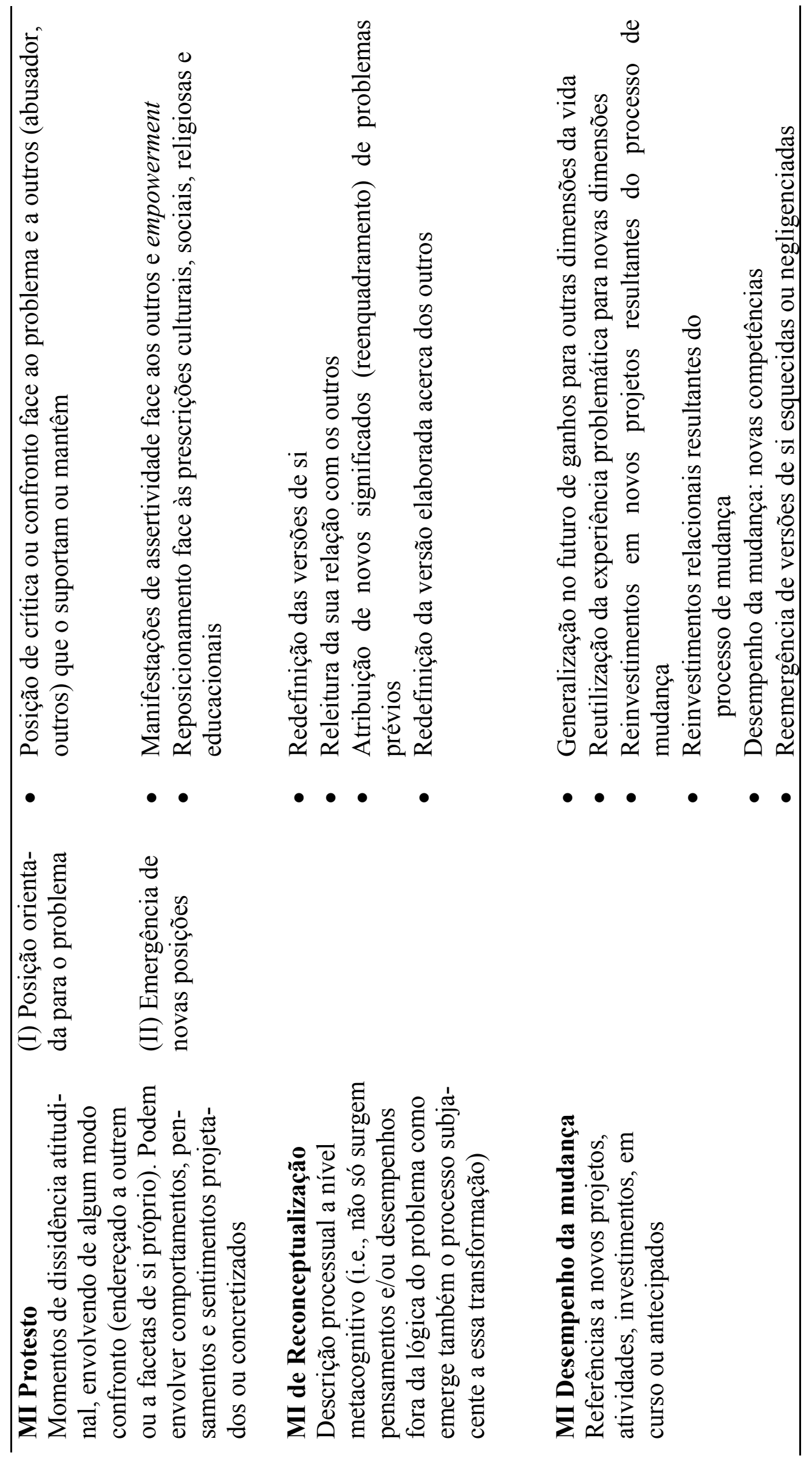




\section{Resultados}

\section{Momentos de inovação}

Apesar da presença de diversos sintomas e do manifesto impacto do problema na vida destas crianças e jovens, todos eles foram capazes de evidenciar momentos de resistência (i.e., MIs) ao problema, em que pensam, agem ou sentem fora do repertório prescrito pelo problema e de forma a contrariar os efeitos do abuso.

Numa análise global, constatou-se que o tipo de MI mais expressivo nas narrativas dos participantes foi a reflexão, surgindo em todas as entrevistas e destacando-se pela sua duração (duração média de 9.1\%). Os MIs de ação emergem dos discursos de todos os participantes mas observa-se uma duração mais reduzida relativamente aos restantes (duração média de 1\%). Os MIs de protesto emergem em catorze entrevistas (duração média de $1.3 \%$ ), seguidos dos MIs de desempenho da mudança (12 entrevistas) (duração média de $1.3 \%$ ). Os MIs de reconceptualização tiveram uma representação bastante reduzida, surgindo apenas nos discursos de cinco dos participantes (duração média de $2.8 \%$ ).

\section{Momento de Inovação de Ação}

Este tipo de MI, ainda que de forma pouco saliente (varia entre $0.2 \% \mathrm{e}$ 2.6\%; duração média: 1\%), emerge dos discursos dos dezasseis participantes. O conteúdo dos MIs de ação surge relacionado com a implementação de estratégias de combate ao problema e seus efeitos, nomeadamente, estratégias de distração, relatadas por catorze $(87,5 \%)$ dos participantes ["Tento ir brincar, andar de bicicleta, jogar à bola, jogar computador para me esquecer"; "Tento coisas que tenham movimento e que tenho muito interesse em fazê-las”].

A revelação do abuso a outros significativos ou às instâncias formais é igualmente referida como ação de desafio ao problema por nove (56\%) dos participantes ["Eu comecei a falar, a falar, a falar, e quando dei por ela, já tinha contado tudo"; "Eu cheguei a um certo ponto que tive mesmo de contar"]. Entre os MI de ação, surge ainda referência a procura de suporte (6; $37.5 \%$ ) ["Às vezes, desabafava com algumas pessoas e tipo... contava o que aconteceu". "Então, eu vou falar com os meus amigos"], a falar/escrever sobre o problema $(5 ; 31 \%)$ [ "Foi falar sobre ele (...) isso foi o mais importante. Falar sobre ele para me sentir mais aliviada"; "Foi então que decidi pegar num caderno e comecei a escrever"'], e a comportamentos de coping (e.g., assertividade face ao grupo de pares, ignorar ativo) perante algumas dificuldades, designadamente medos e/ou reações dos outros $(3 ; 18.7 \%)[$ [“É 
assim: eu arrumei a agenda. Há um ano que não toco nela. Só que hoje fui buscar um livro que queria ver e encontrei-a porque estava lá à beira desse livro. Então, lembrei-me de a trazer"'].

\section{Momento de Inovação de Reflexão}

Os MIs de Reflexão surgem nas narrativas de todos os participantes com uma duração que varia entre $1.5 \%$ a $16 \%(M=9.1 \%)$. A elevada duração dos momentos de reflexão suscitou a necessidade de uma análise mais circunstanciada ao nível dos conteúdos dos MIs desta tipologia, o que permitiu agrupar as reflexões em dois subtipos, de acordo com o manual de codificação adotado (Gonçalves, Ribeiro, Matos, Santos \& Mendes, 2010): 1) reflexões centradas no problema (subtipo I); e 2) reflexões centradas no processo de mudança/recuperação experienciado pelas vítimas de forma espontânea, desde a ocorrência do abuso até ao momento atual (subtipo II).

Os primeiros favorecem a distância da narrativa problemática e incluem essencialmente pensamentos adaptativos e autoinstruções de resistência e perseverança, sendo elementos discursivos frequentes nas narrativas proferidas $(12.8 \%$ da duração dos MI de reflexão) ["Ás vezes sinto-me melhor, tomo decisões e faz-me sentir uma espécie de força porque eu consegui enfrentar e dá-me forças para enfrentar outra vez (...) eu tenho de tentar seguir em frente e ir com isto até ao fim a ver se consigo terminar isto"]. Incluem, também, referência a novas compreensões e/ou formulações do problema e tomada de consciência acerca das suas causas, dinâmicas e consequências (10.6\%) [ "Mas agora, como já sou maior e já sei o que aconteceu e já sei definir e caracterizar aquilo que aconteceu, claro que sinto nojo, sinto... Não sei explicar. Sinto uma coisa má em relação a ele, sinto uma coisa que não tem explicação"] e intenções e/ou desejos de combater e/ou superar o problema (2.2\%) ["Eu, é sempre a lutar"; "Vou andar mais contra o problema a ver se ele não toma conta de mim"].

As reflexões centradas no processo de mudança espontânea/recuperação (subtipo II), destacam-se $(57.4 \%$ da duração dos MI de reflexão) nos discursos dos participantes, sendo, essencialmente, reflexões que descrevem o processo e estratégias implementadas pelos participantes para ultrapassar a história problemática $(42.6 \%$ das reflexões tipo II). $\mathrm{Na}$ análise deste tipo de reflexões, salienta-se a identificação de aspetos positivos decorrentes da experiência abusiva, designadamente, maior união entre os elementos da família, cessação da violência familiar, novas aprendizagens, melhoria das condições de vida e novas oportunidades [" $E$ assim, ele teve coisas negativas e coisas positivas porque, apesar disto que aconteceu, tivemos mais tempo para estudar, tivemos mais silêncio. Andávamos sempre sobressaltados com medo que ele chegasse e do que ia fazer. É assim, eu acho que é melhor"']. 
Os participantes refletem, ainda, sobre a presença de aliados na resistência ao problema que parecem ter funcionado como facilitadores no processo de recuperação. Entre os aliados interpessoais, o suporte do grupo de pares e a não-estigmatização por parte destes assumem particular relevância; igualmente fundamental é o suporte parental e familiar, no sentido de ser acreditada e protegida por estes [" $A$ minha família apoiava-me sempre, diziam sempre que ele fez e também tem que pagar por isso, que se eu ficasse calado era pior para mim, aquilo ia ficar comigo toda a vida"]. É também de realçar o apoio de professores (e.g., validação da experiência, promoção da socialização, disponibilidade para falar sobre o problema, não estigmatização) e o apoio de outros profissionais através da validação de competências e da desmistificação de algumas crenças ["Talvez a psicóloga, que me dizia que a culpa não era minha, que eu não tinha culpa de ter o pai que tive (...) ter dito que não era a única a quem isso tinha acontecido"; "Os professores. Ajudaram-me a conviver com os amigos. Para estar com eles, para fazer as coisas normais")].

Em termos de recursos pessoais relevantes para a mudança, distinguem-se a revelação e o seu significado libertador, a expectativa de justiça, as crenças religiosas e a construção de novas significações para o self (e.g., corajoso, forte, capaz), que reforçam a perceção de competência pessoal e sentido de controlo dos participantes ["Sim, acreditar em Deus foi importante (...) pensava que ele me ia ajudar (...) e pedia muitas vezes para ele me ajudar (...) sim... deu-me força para enfrentar o problema"; "Sei que consegui passar isso (...) tive capacidade para passar por isso, fui corajoso em passar por isso"]. Concomitantemente, envolvem sentimentos de autovalorização e validação pessoal mediante o reconhecimento das qualidades pessoais (8\%) ["Sinto-me bem e sinto-me feliz por eu conseguir tirá-lo da cabeça. Porque eu podia ficar em casa, a olhar para o balão e ele 'tar-me ali a massacrar, a massacrar, mas não"], dimensões da vida não dominadas pelo problema (4.4\%) [A minha namorada estar perto. Parece que me tira o problema do pensamento (...) ela estar perto de mim, eu estar perto dela. Assim, já não me faz pensar. Só me faz pensar em alegria por ela estar comigo"], e menção a desafios ao problema (2.4\%) ["Há alturas em que consigo. Há sempre aquelas alturas em que penso: Não vou pensar nisso, já acabou, esquece. Meto isso para trás das costas e vou passear lá para fora, vou jogar à bola, vou-me distrair e depois esqueço. Tento ao máximo esquecer aquilo que eu não quero que esteja na minha cabeça"].

\section{Momento de Inovação de Protesto}

Os momentos de inovação de protesto evidenciam-se em catorze entrevistas $(87.5 \%)$, variando em termos de duração entre $0.1 \%$ e $5.8 \%(M=$ $1.3 \%$ ). Também aqui foi utilizada a diferenciação entre Protesto de tipo I e 
de tipo II, sugerida pelos autores (SCMI; Gonçalves, Ribeiro, Mendes, Matos, \& Santos, 2011). Foi possível identificar MIs de protesto associados a uma posição orientada para o problema (subtipo I), em que a criança e/ou jovem assume uma postura crítica relativamente ao abusador e a outros que alimentam o problema ["Como é de maior idade devia ter pensado mais antes de me ter feito isso, devia ter pensado que eu era um menor"]. Concomitantemente, surgem ainda protestos que refletem a emergência de novas posições (subtipo II), designadamente, manifestações de assertividade face ao abusador e aos outros ["Eu quero lá saber das pessoas, o que elas vão pensar. A vida é minha e não posso estar sempre a pensar nisso e não é por causa disso que eu não arranjo namorado'], bem como reposicionamento face às expectativas sociais/culturais associadas à experiência de abuso [" $E$ eu não sou nenhuma coitadinha. Não gosto que as pessoas digam isso. Aconteceu, como acontece às outras pessoas, também"].

\section{Momento de Inovação de Reconceptualização}

A referência a momentos de inovação de reconceptualização é escassa, surgindo apenas em seis das entrevistas (37.5\%), variando entre uma duração de $0.8 \%$ e $5.9 \%(M=2.8 \%)$. Nos MIs de Reconceptualização, os participantes assumem uma posição de contraste entre a sua vivência anterior e atual do problema, refletindo acerca do processo de mudança e/ou recuperação. O seu conteúdo relaciona-se com a redefinição das versões de si, designadamente, com uma desvinculação da posição de vítima, identificação de novas capacidades, valorização pessoal e sentimentos de bem-estar ["Antes, eu não tinha noção do mundo ou das coisas más do mundo. Agora tenho. Estes últimos dois anos mudaram completamente a minha cabeça. E, ainda por cima, estou numa idade de adolescência em que se muda muita coisa. Mas eu sinto que mudei mais do que os outros, porque os outros mudaram só a maneira de pensar e eu mudei a maneira de pensar e de ver as coisas (...) consigo encontrar diferenças na nova A. (...) a de conseguir gerir os sentimentos ].

A reconceptualização evidencia-se, ainda, na capacidade que alguns participantes têm de reenquadrar o problema e os seus efeitos, através de uma reflexão sobre a etiologia, dinâmicas e consequências associadas ao abuso e reposicionamento face às suas prescrições ["Aconteceu porque tinha medo de namorar com alguém, que soubessem o que se tinha passado e já não quisessem namorar comigo por causa disso. Foi mais o que eu pensei no princípio. Mas depois comecei a pensar de maneira diferente: que isso pode acontecer a qualquer pessoa e que não tem nada que interferir no namoro"]. Além disso, revelam também a capacidade de atribuir de novos significados à experiência de abuso e de ser capaz de perceber diferentemente os outros, identificando-os como aliados da mudança ou do problema 
['Eu acho que não é uma coisa que marque para toda a vida mas ao princípio é sempre muito marcante. Mas depois, se soubermos lidar com o problema, acho que as coisas são muito mais fáceis de resolver. Ao princípio, pensei que isso me ia marcar para sempre e que nunca ia esquecer. Realmente, a gente nunca esquece mas não é uma coisa que fique sempre, para a gente estar sempre triste. Marca-me naqueles momentos em que estou mais triste, quando estamos mais sozinhos ou não temos ninguém para falar. É quando marca mais. Mas, se soubermos pensar em coisas boas e soubermos passar o tempo de forma que a gente se sinta bem, acho que não marca assim tanto”].

\section{Momento de Inovação de Desempenho da mudança}

Os MIs de desempenho da mudança estão presentes em treze das narrativas analisadas $(81 \%)$, com uma duração que varia entre $0.3 \%$ e $6 \%(\mathrm{M}=$ $1.3 \%$ ). Estes momentos contemplam essencialmente a reutilização da experiência problemática para outras situações antecipadas de vitimação sexual e para novas situações ["Eu acho que o mais importante é as pessoas que passaram por isso terem ajuda e terem apoio. Isso é muito importante. Essas pessoas que passaram por isso terem ajuda e terem apoio é muito importante porque se elas notarem que alguém as vai ajudar é o essencial. Essas pessoas vão ultrapassar a fase do medo, a fase da vergonha, vão ultrapassar tudo. Para mim foi assim”], bem como o reconhecimento de ganhos (novas capacidades, qualidades, competências) e generalização destes no futuro para outras dimensões da vida, e a definição de objetivos e projeção de um futuro liberto da influência do problema ["Eu sei que vou ter de continuar a não ter medo de descobrir coisas novas, apesar de elas me meterem medo. Por exemplo, se um dia tiver um problema que me leve... Por exemplo, um problema que me leva ao Tribunal ou assim... Já sei como é que hei de reagir: tenho de levar as coisas pela verdade e... Como é que eu hei de dizer? Eu acho que isto valeu a pena e que vai ser bom no futuro (...) Esta experiência pôs-me a pensar muito, como eu digo. Um dia que eu tenha filhos ou que uma amiga venha dizer: "Será que eu faço isto", eu não digo "Não faças". Digo: "Vai, mas tem cuidado com isto e com isto"].

\section{Discussão}

O presente estudo tinha como objetivo explorar os recursos narrativos das crianças e/ou jovens vítimas de abuso sexual no sentido de construírem ações e significações preferenciais face à versão problemática do abuso. Globalmente, os resultados refletem uma considerável diversidade de momentos de inovação reportados pelas vítimas. Os dados obtidos corroboram a premissa 
de White e Epston (1990) de que em todas as narrativas problemáticas é possível identificar competências e dimensões da experiência que escaparam à influência do problema e que desafiam a narrativa dominante.

O momento de inovação mais saliente e expressivo nas narrativas dos participantes é a Reflexão, dado congruente com os resultados que têm vindo a ser encontrados nos estudos com os MI na mudança terapêutica (e.g. Matos, 2006; Santos, 2008) e na mudança espontânea (Cruz, 2008; Meira, 2010). Este tipo de MI inclui dois níveis distintos: reflexões centradas no problema (Subtipo I) e reflexões centradas no processo de mudança/recuperação (Subtipo II), sendo de referir que no presente trabalho o subtipo II é mais saliente. Ao nível do primeiro tipo de reflexões, os pensamentos adaptativos e autoinstruções de resistência e perseverança são os elementos discursivos mais frequentes nas narrativas produzidas. Estes elementos discursivos parecem refletir a capacidade adaptativa dos menores relativamente às consequências da revelação da experiência abusiva, em particular, no que diz respeito ao processo judicial (e.g., morosidade dos procedimentos judiciais e dificuldades inerentes). Além disso, a referência a novas compreensões e/ou formulações do problema e a tomada de consciência por parte dos participantes acerca das suas causas, dinâmicas e consequências é também muito importante na medida em que poderá funcionar como alternativa aos discursos de autoculpabilização.

Relativamente às Reflexões centradas no processo de mudança/recuperação, estas envolvem sentimentos de autovalorização e validação pessoal mediante a identificação das qualidades pessoais, de dimensões da vida não dominadas pelo problema e da menção de desafio ao problema. Assim, o reconhecimento por parte dos participantes da existência de recursos pessoais capazes de confrontar o problema reflete a identificação do seu papel fundamental de "ator" da experiência e não de mera vítima passiva da mesma. De facto, as reflexões que descrevem o processo e as estratégias implementadas pelos participantes para ultrapassar a história problemática são as que maioritariamente caracterizam os seus discursos. Mais especificamente, a identificação de aspetos positivos decorrentes da experiência abusiva (e.g., maior união entre os elementos da família, cessação da violência familiar, novas aprendizagens, melhoria das condições de vida e novas oportunidades) e de aliados na resistência ao problema parecem ser as reflexões mais relevantes na reelaboração do significado do abuso. Estes resultados são teoricamente plausíveis, na medida em que alguns estudos demonstraram que as inovações cognitivas que salientam elementos positivos decorrentes da experiência abusiva se associam a maiores níveis de ajustamento (Himelein, \& McElrath, 1996; Plasha, 2009).

Por sua vez, os aliados não só funcionam como facilitadores no processo de recuperação como também permitem a validação de competências e 
desmistificação de algumas crenças das crianças e/ou jovens. De salientar o suporte do grupo de pares e a não-estigmatização por parte destes como o "aliado" mais significativo, resultado também referenciado em vários estudos que envolveram crianças e jovens vítimas de abuso (Collishaw, Pickles, Messer, Shearer, \& Maugham, 2007; Dufour, Nadeau, \& Bertrand, 2000; Dumont, Widom, \& Czaja, 2007). Com efeito, alguns estudos confirmam que as crianças e/ou jovens vítimas que dispõem de suporte e não são alvo de estigmatização por parte dos seus pares, evidenciam maior adaptação psicológica (Dufour, Nadeau, \& Bertrand, 2000). De igual modo, a proeminência do grupo de pares relativamente a outros aliados é facilmente compreendida se atendermos ao facto de este se assumir como uma audiência privilegiada na etapa desenvolvimental em que os participantes se encontram. Neste sentido, dados empíricos corroboram este resultado, demonstrando que o suporte dos pares assume uma poderosa influência no desenvolvimento da resiliência nas vítimas, particularmente nesta fase de desenvolvimento (Collishaw, Pickles, Messer, Shearer, \& Maugham, 2007; Rosenthal, Feiring, \& Taska, 2003). Concomitantemente, segue-se o suporte parental e familiar, considerado por vários autores como o principal preditor do reajustamento após o trauma (Deblinger \& Heflin, 1996; Fergusson \& Mullen, 1999; Saywitz et al., 2000; Tremblay, Hébert and Piché, 1999; Wolfe, 1999) e o apoio de professores (e.g., validação da experiência, promoção da socialização, disponibilidade para falar sobre o problema, não estigmatização), elementos também considerados relevantes no processo de restabelecimento das vítimas (Leathy, Pretty, \& Tenenbaum, 2003; Plasha, 2009; Runtz \& Schallow, 1997).

Em termos de "recursos/aliados" pessoais para a mudança, distinguem-se a revelação e o seu significado libertador, a expectativa de justiça, as crenças religiosas e a construção de novas significações para o self (e.g., corajoso, forte, capaz), que reforçam a perceção de competência pessoal e sentido de controlo dos participantes. Este sentido de controlo torna-se particularmente relevante na forma como a criança lida com a experiência abusiva, na medida em que lhe permitirá a adoção de comportamentos adaptativos face ao problema. Efetivamente, a literatura sugere que um "locus de controlo interno" tende a estar associado a uma atitude proativa por parte dos indivíduos (Demellow \& Imms, 1999), bem como ao seu restabelecimento adaptativo (e.g., Barros, \& Sani, 2010; Himelein \& McElrath, 1996; Valentine \& Feinauer, 1993; Dufour, Nadeau, \& Bertrand, 2000; Heller, Larrieu, D’Imperio, \& Boris, 1999). Além disso, a construção de novas significações para o self traduz a capacidade da criança elaborar uma narrativa alternativa àquela que caracterizava o episódio abusivo (e.g., a culpa e a vergonha são reconstruídas, passando a um discurso que enfatiza a capacidade, coragem e competência). Estes resultados são congruentes com os obtidos num estudo qualitativo com uma amostra de homens adultos vítimas de abuso sexual na 
infância (Kia-Keating, Grossman, \& Epstein, 2005) que verificou uma associação de significados de competência, força e coragem a um maior ajustamento psicológico.

De salientar que o desafio ao problema também se concretiza, embora com menor relevo, através dos MIs de Ação, Protesto e Desempenho da Mudança. O conteúdo dos MIs de Ação surge relacionado com a implementação de estratégias de combate do problema e dos seus efeitos, nomeadamente estratégias de distração e a revelação do abuso a outros significativos ou às instâncias formais. Alguns estudos (Dufour, Nadeau, \& Bertrand, 2000) têm salientado a procura ativa de suporte e a revelação a outros como estratégias que aumentam a autoconfiança e o sentido de controlo. Por sua vez, a revelação judicial do abuso, nos casos em que esta é voluntária e consciente e em que as respostas são adequadas, parece funcionar como uma estratégia ativa de coping bem-sucedida, apesar de precipitar um agravamento sintomático inicial (Dufour, Nadeau, \& Bertrand, 2000), tal como já sinalizámos anteriormente. De modo análogo, há referências empíricas que sugerem que a procura de atividades favorecedoras de emoções positivas se constitui como uma estratégia de coping adaptativa (Morrow \& Smith, 1995), dados congruentes com os resultados obtidos no presente estudo.Não obstante, este é um elemento ainda pouco explorado no âmbito da investigação neste domínio.

As estratégias de combate ao problema incluem ainda o confronto/crítica relativamente ao abusador e a outros fatores sociais que alimentam o problema, sendo este um elemento fundamental dos MIs de Protesto. Este tipo de MI inclui a emergência de novas posições (e.g., manifestações de assertividade face ao abusador e aos outros), bem como um reposicionamento face às expectativas sociais/culturais associadas à experiência de abuso. Esta reconstrução das significações de culpa e vergonha, inicialmente associadas à experiência abusiva, traduz a capacidade de as vítimas se tornarem "agentes" ativos de resolução do problema (White \& Epston, 1990).

A emergência de novas posições, patentes nos MIs de Reflexão e Protesto, estão também subjacentes aos MIs de Desempenho da Mudança, na medida em que os participantes parecem reutilizar a experiência problemática para antecipar como poderiam lidar de forma adaptativa com outras situações de ameaça. O reconhecimento de ganhos (novas capacidades, qualidades, competências) e a generalização destes no futuro para outras dimensões da vida torna-se fundamental para o confronto e superação do problema, refletindo-se na definição de objetivos e projeção de um futuro liberto da influência do abuso. Efetivamente, do ponto de vista de White e Epston (1990), os indivíduos estão capazes de desenvolver uma narrativa adaptativa acerca de si quando desconstroem os efeitos desadaptativos do problema e focalizam a sua atenção nos momentos de inovação, recontando a sua histó- 
ria a partir deste novo ponto de vista. Importa salientar que este estudo revela uma incidência moderada de momentos de inovação de desempenho da mudança, sendo este um dado inesperado face à literatura disponível. No entanto, este resultado poderá estar relacionado com a especificidade da amostra, designadamente pelo facto de as crianças e jovens, pelas suas características desenvolvimentais, estarem mais capazes de reportar mudanças objetivamente observáveis, e menos formulações de generalização no abstracto. Além disso, é também possível que a maior propensão para a imaginação nesta etapa desenvolvimental - tipicamente utilizada na resolução de problemas - (Hewitt, 1999), possa explicar a maior projeção no futuro de cenários positivos alternativos por parte dos participantes.

Os MIs de Reconceptualização são, por último, aqueles que apresentam uma representação mais reduzida nesta amostra, apesar de outros estudos, com população adulta, terem evidenciado a sua relevância no processo de mudança (e.g., Gonçalves, Cunha, Ribeiro, Mendes, Santos, Matos, \& Salgado, 2010; Matos, 2006; Matos, Santos, Gonçalves, \& Martins, 2009). Este resultado poderá estar relacionado com o facto de este tipo de MI exigir, por definição, o "envolvimento de uma metaposição sobre a mudança [...] e a capacidade de este observar o que se está a tornar diferente do "guião" anterior e os novos caminhos que pode percorrer na narrativa em construção" (Santos, 2008, p. 34). Efetivamente, apesar de a adolescência ser um período desenvolvimental caracterizado pela capacidade crescente de construção individual do significado associado às experiências de vida (Bluck \& Habermas, 2001), a capacidade de raciocínio autobiográfico está ainda pouco maturada nesta fase desenvolvimental (Singer \& Bluck, 2001). Não obstante, importa salientar que, nos participantes em que este tipo de MI está presente, a posição das crianças/adolescentes caracteriza-se pelo contraste entre a vivência anterior e atual do problema, refletindo uma ponderação acerca do processo de mudança e/ou recuperação. O conteúdo deste tipo de MI relaciona-se com a redefinição das versões de si, designadamente, com uma desvinculação da posição de vítima, identificação de novas capacidades, valorização pessoal e sentimentos de bem-estar. A reconceptualização evidencia-se ainda na capacidade que alguns participantes têm de reenquadrar o problema e os seus efeitos (e.g., reflexão sobre a etiologia, dinâmicas e consequências associadas ao abuso e reposicionamento face às suas prescrições), de atribuir novos significados à experiência de abuso e de ser capaz de perceber diferentemente os outros, identificando-os como aliados da mudança ou do problema.

Muito embora os estudos previamente realizados neste domínio salientem os MI de reconceptualização como um elemento essencial ao desenvolvimento de uma história preferencial (Gonçalves, Matos, \& Santos, 2009; Gonçalves et. al., 2010), as especificidades desenvolvimentais da pre- 
sente amostra poderão, efetivamente, influenciar os resultados obtidos e discutidos neste trabalho. Com efeito, a dificuldade das crianças e jovens se reposicionarem meta-cognitivamente poderá influenciar a sua capacidade de formular narrativas alternativas, de forma integrada e complexa, face à narrativa problemática. No entanto, a maior saliência observada de momentos de inovação de reflexões centradas no processo de mudança (subtipo II), leva-nos a considerar como hipótese o facto de estas reflexões se constituírem um percursor significativo da mudança e reconstrução narrativa mais consonante com as características desenvolvimentais destas crianças/jovens.

\section{Limitações e implicações}

Os resultados obtidos no presente estudo evidenciaram contribuições importantes de uma abordagem narrativa à compreensão dos recursos e competências de crianças/jovens vítimas de abuso sexual, no sentido da mudança. Não obstante, importa reconhecer e refletir sobre algumas limitações. Em primeiro lugar, as características da amostra, pela sua dimensão reduzida e pelo facto de muitas constituírem situações de abuso que ainda não transitaram em julgado, limitam a transferenciabilidade (Glaser \& Strauss, 1967). De modo semelhante, as especificidades que nortearam o presente estudo (e.g., amostra infantil com menos capacidades metacognitivas e de relato autobiográfico comparativamente aos adultos, estudo da mudança espontânea, existência de um único momento de avaliação), tornaram igualmente este trabalho muito distinto dos restantes estudos já conduzidos neste domínio com recurso ao modelo narrativo. Finalmente, e tomando em consideração que a análise dos momentos de inovação com crianças e adolescentes é inovadora neste domínio de investigação, a própria grelha de codificação destes momentos poderá não ser completamente adequada às características desenvolvimentais dos participantes, merecendo estudos futuros.

Não obstante as limitações mencionadas, consideramos que o presente estudo sugere indicadores importantes para a investigação e para prática. Neste sentido, do ponto de vista da investigação, o modelo narrativo oferece uma leitura explicativa específica e integrativa sobre o impacto do abuso sexual e os recursos de coping dos menores vítimas, comparativamente com os outros modelos teóricos (gerais ou mais específicos ao abuso). Concomitantemente, o presente estudo permitiu obter um entendimento aprofundado acerca dos recursos pessoais de que estas vítimas dispõem para fazer face a esta adversidade e para caminhar no sentido da mudança, nomeadamente no que diz respeito à forma como conseguem articular e elaborar um conjunto de ações, afetos, cognições e projetos que escapam à influência do problema e abrem portas ao desenvolvimento de trajetórias resilientes. Estes resultados 
sugerem assim que o desafio para investigadores e profissionais no contexto de intervenção no âmbito do abuso sexual passa por compreender a experiência abusiva enquanto integrada em contextos desenvolvimentais diferenciados - familiar e comunitário - (Jaffee, Caspi, Moffitt, Polo-Tomas, \& Taylor, 2007) que influenciam de forma relevante o menor ou maior impacto da experiencia abusiva. Concomitantemente, e no que aos procedimentos judiciais diz respeito, não só se mostra fundamental a implementação de procedimentos e diligências que melhor salvaguardem as vítimas, mas também que promovam o seu empowerment (e.g., fomentar maior envolvimento e participação ativa das vítimas nos processos/decisões judiciais).

É nossa expectativa que este estudo se traduza em novas investigações e práticas neste domínio de estudo, que possam ultrapassar as limitações apresentadas e contribuir para que a experiência adversa do abuso sexual, se traduza, cada vez mais, num impacto minorado nas vítimas. Do mesmo modo, o estudo sistemático dos recursos e potencialidades aqui explorados permitam compreender de que forma estas crianças e jovens constroem percursos preferenciais, no sentido da mudança e da resiliência.

\section{Referências}

Adams-Westcott, J., \& Dobbins, C., (1997) Listening with your "heart ears" and other ways young people can escape the effects of sexual abuse. In C. Smith \& D. Nylund (Eds), Narrative therapies with children and adolescents (pp.195-220). New York: The Guilford Press.

Barros, D. \& Sani, A. I. (2010). Coping e resiliência em crianças vítimas de abuso sexual. Atas do VII Simpósio Nacional de Investigação em Psicologia, Universidade do Minho, Portugal, 4 a 6 de fevereiro.

Bluck, S. \& Habermas, T. (2001). Extending the study of autobiographical memory: Thinking back about life across the life span. Review of General Psychology, 5, $135-147$.

Bronfenbrenner, U. (1994). Ecological models of human development. In International Encyclopedia of Education, vol. 3 (second edition). Oxford: Elsevier.

Cicchetti, D., \& Lynch, M. (1995). Failures in the expectable environment and their impact on individual development: the case of child maltreatment. In D. Cicchetti \& D. Cohen (Eds.). Developmental Psychopathology. Risk, Disorder, and Adaptation (Vol. 2). New York: John Wiley.

Collishaw, S. Pickles, A., Messer, J., M., Shearer, C., \& Maugham, B. (2007). Resilience to adult psychopathology following childhood maltreatment: Evidence from a community sample. Child Abuse \& Neglect, 31, 211-229.

Cruz, G. \& Gonçalves, M. M. (2010). Momentos inovativos e mudança espontânea: Um estudo exploratório. Psychologica, 53, 67-80.

Deblinger, E. \& Heflin, A.A (1996). Treating sexually abused children and their non-ofending parents. A cognitive behavioral approach. Thousand Oaks: Sage. 
Demellow, L.R. and Imms, T., (1999). Self esteem, locus of control, and coping styles and their relationship to school attitudes of adolescents. Psychological Studies 44, 24-34.

Dufour, M.H., Nadeau, L. \& Bertrand,K. (2000). Les facteurs de resilience chez les victims d'abus sexuel: état de la question.Child Abuse \& Neglect, 24, 781-797.

DuMont, K., Widom, C., \& Czaja, S. (2007). Predictors of resilience in abused and neglected children grown up: the role of individual and neighborhood characteristics. Child Abuse \& Neglect, 31, 255-274.

Fergusson, D., \& Mullen, P. (1999). Childhood sexual abuse: An evidence based perspetive. Thousand Oaks: Sage publication.

Finkelhor, D. (1990). Early and Long-Term Effects of Child Sexual Abuse: An update. Professional Psychology: Research and Practice, 21, 325-330.

Flick, U. (2002). An introduction to qualitative research. Thousand Oaks: Sage publication.

Freedman, J., \& Combs, G. (1996). Narrative therapy: The social construction of preferred realities. New York: Norton.

Glaser, B. \& Strauss, A. (1967). Discovery of Grounded Theory. Chicago: Aldine

Gonçalves, M. (2008). Terapia narrativa da reautoria: o encontro de Bateson, Bruner e Foucault. Coleção de Cadernos de Psicoterapia, 2. Braga: Psiquilíbrios Edições.

Gonçalves, M. M., Cunha, C., Ribeiro, A., Mendes, I., Santos, A., Matos, M., \& Salgado, J. (2010). Innovative moments in psychotherapy: dialogical processes in developing narratives. In M. Märtsin, B. Wagoner, L. Whittaker, E-M. Aveling \& I. Kadianaki (Eds). Dialogical science. The self in communication culture and society. New York: Nova Science Publishers.

Gonçalves, M. M., \& Henriques, M. R. (2000). Terapia narrativa da ansiedade. Coimbra: Quarteto.

Gonçalves, M. M., Matos, M., \& Santos, A. (2009). Narrative therapy and the nature of "unique outcomes" in the construction of change. Journal of Constructivist Psychology, 22, 1-23.

Gonçalves, M. M., Ribeiro, P. A., Mendes, I., Matos, M., \& Santos, A. (2011). Tracking Novelties in Psychotherapy Process Research: The Innovative Moments Coding System. Psychotherapy Research, 21, 497-509.

Jaffee, S., R., Caspi, A., Moffitt, T., E., Polo-Tomas, M., \& Taylor, A. (2007). Individual, family and neighborhood factors distinguish resilient from non-resilient maltreated children: A cumulative stressors model. Child Abuse \& Neglect, 31, 231-253.

Joyce-Moniz, L. (1993). Psicopatologia do desenvolvimento do adolescente e do adulto. Lisboa: McGraw-Hill

Harker, T. (1997). Therapy with male sexual abuse survivors: Contesting oppressive life stories. In G. Monk, J. Winslade, K. Crocket, \& D. Epston (Eds.), Narrative therapy in practice: The archaeology of hope (pp.193-214). San Francisco: Jossey-Bass.

Haugaard, J. (2000). The challenge of defining child sexual abuse. American Psychologist, 55, 1036-1039. 
Heller, S.S., Larrieu, J.A., D`Imperio, R. \& Boris, N.W. (1999). Research on Resilience to Child Maltreatment: Empirical Considerations. Child Abuse \& $\mathrm{Ne}-$ glect, 23, 321-338.

Himelein, M. J. \& McElrath, J. A. (1996). Resilient child sexual abuse survivors. Cognitive coping and illusion. Child Abuse \& Neglect, 20, 747-758.

Kendall-Tackett, K., Williams, L. \& Finkelhor, D. (1993). Impact of sexual abuse on children: a review and synthesis of recent empirical studies. Psychological Bulletin, 113, 164-180.

Kia-Keating, M., Grossman, F. K., Sorsoli, L., \& Epstein, M. (2005). Containing and resisting masculinity: Narratives of renegotiation among resilient male survivors of childhood sexual abuse. Psychology of Men and Masculinity, 6, 169-185.

Leathy, T., Pretty, G., \& Tenenbaum, G. (2003). Childhood sexual abuse narratives in clinically and nonclinically distressed adults survivors. Professional Psychology: Research and practice, 34, 657-665.

Machado, C. (2002). Abuso Sexual de crianças. In C. Machado \& R. Gonçalves (Eds) Violência e Vitimas de Crimes vol.2 (pp. 40-93). Coimbra: Quarteto Editores.

Machado, C., \& Gonçalves, M. M. (1999). Psicoterapia com crianças abusadas sexualmente: da catarse à reautoria. Psicologia: Teoria, Investigação e Prática, 2, 347-354.

Matos, M. (2006). Violência nas relações de intimidade. Estudo sobre a mudança psicoterapêutica na mulher. Dissertação de Doutoramento em Psicologia, na área de conhecimento de Psicologia da Justiça, apresentada ao Instituto de Educação e Psicologia, Universidade do Minho.

Matos, M., Santos, A., Gonçalves, M., \& Martins, C. (2009). Innovative moments and change in narrative therapy. Psychotherapy Research, 19, 68-80.

Meira, L., Gonçalves, M. M., Salgado, J. \& Cunha, C. (2009). Everyday life change: Contribution to the understanding of daily human change. In M. Todman (Ed.), Self-Regulation and social competence: Psychological studies in identity, achievement and work-family dynamics (pp.145-154). Athens: ATINER

Morrow, S.L. \& Smith, M.L. (1995). Constructions of Survival and Coping by Women Who Have Survived Childhood Sexual Abused. Journal of Counseling Psychology January, 42, 24-33.

Morse, J. M.(1994). Designing founded qualitative research In N. K. Denzin \& Y. S. Lincoln (Eds). Handbook of Qualitative Research (pp. 220-235). Thousand Oaks: Sage.

Plasha, T. (2009). Educational resilience among African survivors of child sexual abuse in South Africa. Journal of Black Studies, 5, 1-20.

Qualitative Solutions \& Research (1997). Non-numerical Unstructured Data - Indexing, Searching and Theorizing - NUD*IST. EDITOR

Rosenthal, S., Feiring, C. \& Taska, L. (2003). Emotional support and adjustment over a year's time following sexual abuse discovery. Child Abuse \& Neglect, 27, 641-661. 
Runtz, M. G., \& Schallow, J. R. (1997). Social support and coping strategies as mediators of adult adjustment following childhood maltreatment. Child Abuse and Neglect, 21, 211-226.

Santos, A. (2008). Mudança Narrativa no Processo Terapêutico de Re-Autoria. Dissertação de Doutoramento em Psicologia, na área de conhecimento de Psicologia Clínica, apresentada ao Instituto de Educação e Psicologia, Universidade do Minho.

Saywitz, K., Mannarino, A., Berliner, L. \& Cohen, J. (2000). Treatment for Sexually Abused Children and Adolescents. American Psychologist, 55, 1040-1049.

Singer, J. A. \& Bluck, S. (2001). New perspetives on autobiographical memory: The integration of narrative processing and autobiographical reasoning. Review of General Psychology, 5, 1-99.

Soares, I. (2000). Introdução à psicopatologia do desenvolvimento: questões teóricas e de investigação. In I. Soares (Coord), Psicopatologia do desenvolvimento: trajetórias (in)adaptativas ao longo da vida. (pp. 11-42) Coimbra: Quarteto Editora

Tremblay, C., Hébert, M. \& Piché, C. (1999). Coping strategies and social support as mediators of consequences in child sexual abuse victims. Child Abuse \& Neglect, 23, 929-945.

Valentine L., \& Feinauer, L. L. (1993). Resilience factors associated with female survivors of childhood sexual abuse. American Journal of Family Therapy, 32, 216-224.

White, M. (2004). Narrative practices and exotic lives: resurrecting diversity in everyday life. Adelaide: Dulwich Center publications.

Wolfe, D. (1999). Child abuse: implications for child development and psychopathology. Developmental Clinical Psychology and Psychiatry. London: Sage Publications

White, M. \& Epston, D. (1990). Narrative means to therapeutic ends. New York: Norton. 